\title{
Effects of Temperature and Moisture on the Infection and Development of Apple Fruit Rot Caused by Phytophthora cactorum
}

Fang Liu, Bao-hua Li, ${ }^{\dagger}$ Sen Lian, Xiang-li Dong, Cai-xia Wang, Zhen-fang Zhang, and Wen-xing Liang, College of Plant Health and Medicine, Qingdao Agricultural University; Key Lab of Integrated Crop Pest Management of Shandong Province; Qingdao 266109, P.R. China

\begin{abstract}
Phytophthora fruit rot, caused by Phytophthora cactorum, is an important disease of apple in China, often causing more than $50 \%$ fruit rot in rainy years. We examined the effects of temperature and moisture on the development of the disease and effects of the variables on zoospore release and germination, infection, and lesion development. In vitro, a temperature range of 5 to $20^{\circ} \mathrm{C}$ had no significant effects on zoospore release dynamics but did significantly affect the quantities of released zoospores. The largest quantity of zoospores was released at $9.9^{\circ} \mathrm{C}$ according to a fitted model. Zoosporangia released zoospores within $15 \mathrm{~min}$ at the test temperatures $\left(0\right.$ to $\left.20^{\circ} \mathrm{C}\right)$, which peaked at the fourth hour. Zoospores germinated in vitro, requiring free water, at temperatures from 5 to $35^{\circ} \mathrm{C}$. The optimum germination temperature was $25.1^{\circ} \mathrm{C}$ according to a fitted

model. The minimum wetness duration required for zoospores to complete the infection process and induce visible lesions on Fuji fruit was $0.40 \mathrm{~h}$ at the optimal temperature of $23.0^{\circ} \mathrm{C}$ according to the fitted model, whereas observed values were $4.5,1.5,0.5,1.5$ and $8.5 \mathrm{~h}$ at $10,15,20$, 25 , and $30^{\circ} \mathrm{C}$, respectively. The number of zoospore infections on fruit at various temperatures and wetness durations were well fitted by the modified Weibull model; based on the model, the optimal temperature for zoospore infections was $23.0^{\circ} \mathrm{C}$. Young apple fruit infected by zoospores developed visible lesions from 10 to $30^{\circ} \mathrm{C}$, with a predicted optimum of $23.5^{\circ} \mathrm{C}$; no lesions developed at 5 or $35^{\circ} \mathrm{C}$. The shortest incubation period of the disease was 4 days. These results can be used to develop disease forecasting models for improved fungicide control.
\end{abstract}

Phytophthora fruit rot (PFR) of apple, which is caused by Phytophthora cactorum (Lebert \& Cohn) Schröt, is an important disease in China (Cheng and Zhang 1981; Han 1979; Zhou and Zhao 2016). The pathogen is soilborne (Baines 1939; Blackwell 1943; Sneh and McIntosh 1974) and infects the roots and trunks of apple trees, causing collar rot (Banihashemi and Mitchell 1976; Dakwa and Sewell 1981; Gupta and Singh 1979; Matheron et al. 1988; Nakova 2010; Sewell and Wilson 1973a, b; Sewell et al. 1974; Utkhede 1986; Welsh 1942) or crown rot (Jacobs 1994; Jeffers and Aldwinckle 1988; Jung and Blaschke 2004; Spring et al. 1980; Suzui and Hoshino 1979). When the pathogen's spores are dispersed via splashed rainwater, the pathogen infects fruit, causing PFR (Grove and Boal 1991). PFR lesions are moist, light brown or dark green in color, and irregular in shape, with indistinct edges. The lesions extend to the entire fruit within several days and cause fruit decay (Cheng and Zhang 1981; Han 1979; Wang et al. 1991). In China, leaves and shoots can also be infected by the pathogen, causing leaf blight and shoot dieback (unpublished data). In addition to apple trees, the pathogen is responsible for disease in many other crops such as pear, strawberry, peach (Thomidis 2003), and cherry (Grove and Boal 1991; Hantula et al. 2000; Mircetich et al. 1976; Pánek et al. 2016; Thomidis 2001; Webster et al. 2000; Wormald 1919).

To date, there are only a few reports on infection of apple fruit by P. cactorum (Grove and Boal 1991; Wormald 1919) and management practices that can favor the disease. The first PFR report was from England in 1919 (Wormald 1919), followed by a report from the United States in 1991 (Grove and Boal, 1991). In the United

${ }^{\dagger}$ Corresponding author: B. Li; E-mail: Baohuali@qau.edu.cn

Funding: This research was funded by National Key Research and Development Program of China (2016YFD0201122), China Agriculture Research System (CARS-28), Agricultural Science and Technology Innovation Project of Shandong Academy of Agricultural Sciences, Graduate Student Innovation Program of Qingdao Agricultural University (QYC201507), and Taishan Scholar Construction Project of Shandong Province.

Accepted for publication 15 March 2018.

This article is in the public domain and not copyrightable. It may be freely reprinted with customary crediting of the source. The American Phytopathological Society, 2018.
States, PFR is only problematic in regions where $P$. cactorum occurs in irrigation water and where overtree irrigation practices are employed. Other factors that promote PFR in the United States include ground sprinklers with an angle that results in wetting of fruit on lower branches, as well as the use of pathogen-contaminated water for pesticide applications (Grove and Boal 1991). Conversely, most orchards in China have no irrigation system or have only canal irrigation, and the pathogen is not known to occur in irrigation water. In China, PFR is mainly triggered by prolonged periods of rain, with epidemics only occurring approximately once every 2 or 3 years during high rainfall.

Rotted apple fruit due to $P$. cactorum were first reported in China in 1979 (Han 1979), and the symptoms of the disease and the morphology of the pathogen were described. Pathogen infection and development, epidemics, and control of the disease were also studied by Han (1979). Subsequent to 1979, PFR was found throughout the major production areas of China, with the incidence of rotted fruit caused by the disease reaching 50\% (Cheng and Zhang 1981; Han 1979; Liu et al. 1998; Wang et al. 1991; Yang and Liu 1988; Yu et al. 2011). In 1987, the disease led to losses of 51.8\% for Red Delicious and $42.3 \%$ for Golden Delicious apple in orchards in Tai' an (Yang and Liu 1988); in 2011, more than $40 \%$ of apple fruit were destroyed by the pathogen (Yu et al. 2011).

Blackwell (1943) described the detailed life cycle of $P$. cactorum. $P$. cactorum survives as thick-walled oospores or chlamydospores in soil or overwinters as mycelia in cankered lesions on roots and trunks (Horner and Wilcox 1996; Iribarren et al. 2012; Sneh and McIntosh 1974). A large number of oospores and chlamydospores are found in soil in affected orchards (Bhat and Browne 2010; Horner and Wilcox 1996; Jeffers and Aldwinckle 1987; Nowakowska et al. 2016; Sewell et al. 1974; Tsao 1983). In an environment that is favorable for asexual reproduction of the pathogen, a large number of zoosporangia that can release zoospores are produced from mycelia, oospores, or chlamydospores (Gisi and Zentmyer 1980; Harris and Tobutt 1986; McIntosh 1972). Both zoosporangia and zoospores are dispersed by splashed rainwater and deposited onto the surface of fruit. PFR lesions develop on infected fruit within 3 to 5 days (Cheng and Zhang 1981; Han 1979; Wang et al. 1991). In humid environments, clusters of mycelia, consisting of hyphae, sporangiophores, and zoosporangia, form on the surfaces of decayed fruit. The inoculum produced on fruit lesions can contribute to the rapid development of epidemics (Han 1979). 
The occurrence and epidemics of PFR are closely related to the effect of moisture and temperature on the reproductive cycle of the pathogen and subsequent lesion formation. Formation of zoosporangia, from initiation of the sporangiophore to the ripe zoosporangium, requires approximately $6 \mathrm{~h}$ of wetness (Blackwell 1943). It has been reported that chlamydospores readily formed in vitro after incubation for 20 days at $4^{\circ} \mathrm{C}$ and occasionally developed at 24 and $28^{\circ} \mathrm{C}$, whereas no chlamydospores were produced at $8,12,16,20$, or $32^{\circ} \mathrm{C}$. Chlamydospore germination rates after freezing at $-23^{\circ} \mathrm{C}$ for $24 \mathrm{~h}$ were still high (60 to 80\%) (Darmono and Parke 1990). There are few reports involving conditions required for zoospore release from zoosporangia and infection. Grove and Boal (1991) reported that, on immature apple fruit inoculated with $P$. cactorum zoospores, disease incidence and severity increased with wetness duration up to $12 \mathrm{~h}$ at temperatures between 7 and $30^{\circ} \mathrm{C}$. On immature strawberry fruit, infection with $P$. cactorum zoospores was enhanced with increasing wetness duration $(0$ to $5 \mathrm{~h})$ at 6 to $30^{\circ} \mathrm{C}$, and more than $1 \mathrm{~h}$ of wetness resulted in more than $80 \%$ infection (Grove et al. 1985). Crown rot lesions of peach trees caused by $P$. cactorum were able to develop at $35^{\circ} \mathrm{C}$, though maximum development occurred at 20 to $25^{\circ} \mathrm{C}$ (Thomidis 2003).

A few measures have been implemented to manage PFR in China, including spraying of fungicides to control disease development before epidemics, or killing of zoosporangia on the ground. The latter is conducted by applying fungicides such as copper sulfate $\left(\mathrm{CuSO}_{4}\right)$ at a dosage of $1,500 \mathrm{~g} / \mathrm{ha}$ to the orchard soil surface. Alternatively, the orchard ground can be covered with grass or films to prevent pathogen dispersal via rainwater (Han 1979; Liu et al. 1998; Wang et al. 1991).
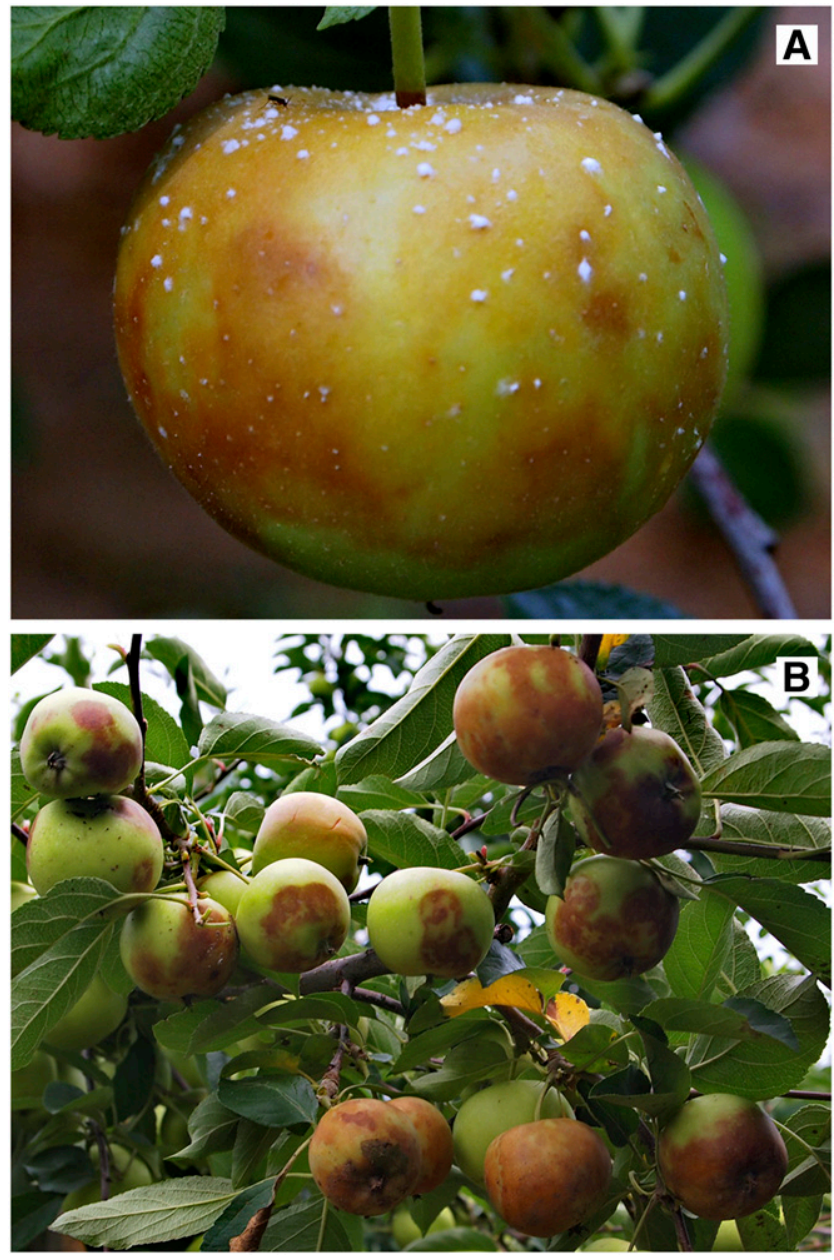

Fig. 1. Phytophthora fruit rot (PFR) lesions caused by Phytophthora cactorum on Fuji fruit in July 2013 in an orchard located in Laizhou, Shandong Province, China. A, Typical Phytophthora rot lesions with clusters of mycelia consisting of hyphae, sporangiophores, and zoosporangia. The lesion is light brown in color and irregular in shape, with indistinct edges. B, PFR fruit on a branch of Fuji tree.
Although it is known that PFR occurrence depends on the duration and total amount of rainfall in China, detailed information regarding the parameters required for infection are not well defined. Thus, opportunities to effectively control the disease have often been missed, leading to serious damage because of difficulty in predicting the weather parameters (temperatures and wetness duration) associated with PFR epidemics. In this study, experiments were conducted to examine the effects of (i) temperature on the release of zoospores from zoosporangia; (ii) temperature, moisture levels, and wetness duration on zoospore germination and infection; and (iii) temperature on disease incubation. The results provide a new understanding of PFR epidemics, and the data can be used to develop models to forecast infection stages and the amount of pathogen inoculum produced during epidemics.

\section{Materials and Methods}

Inoculum and fruit. Fruit of Fuji apple with PFR lesions (Fig. 1) were sampled in July 2013 from an orchard located in Laizhou, Shandong Province, China (E120.142, N37.366). Fruit tissues of $1 \mathrm{~mm}^{3}$ were cut from lesion edges, after the fruit were disinfected for 2 min with $75 \%$ ethyl alcohol, and transferred to carrot juice agar medium (carrot juice/water [1:5] with $2 \%$ agar, sterilized at $121^{\circ} \mathrm{C}$ for $20 \mathrm{~min}$ ) to isolate the pathogen.

Using a capillary of $0.8 \mathrm{~mm}$ in diameter, single hyphal strands were selected from colony edges, yielding eight isolates. The internal transcribed spacer (ITS) region of the ribosomal DNA of the eight

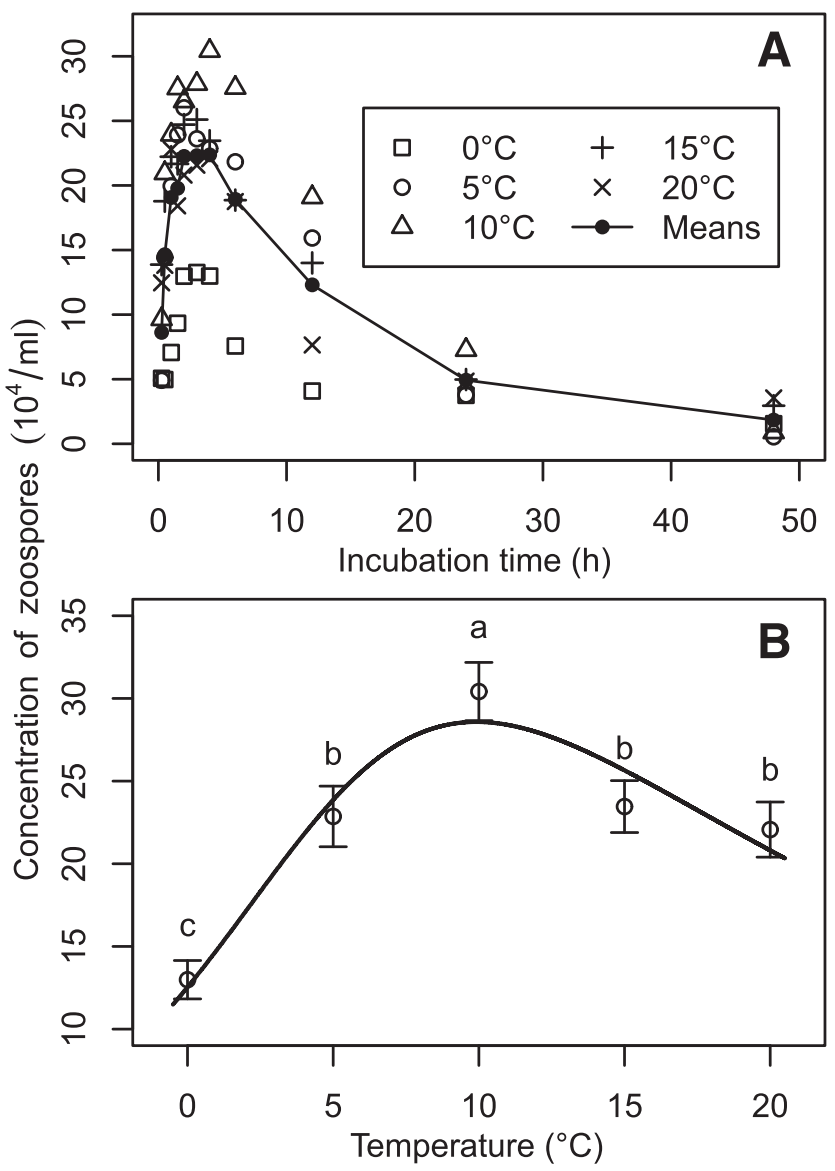

Fig. 2. A, Concentrations of zoospores of Phytophthora cactorum released at different times when zoosporangium suspensions were incubated at five temperatures and $\mathrm{B}$, concentrations of zoospores in suspensions incubated for $4 \mathrm{~h}$ at five temperatures. Circles in B are the means of observed values with standard errors (bar), and solid lines are the curves of the fitted models. Different letters in B indicate significant differences at the level of $\alpha=0.05$ according to multiple comparisons of values predicted by a generalized linear model with Tukey's all-pair comparison test. Zoosporangium suspensions were obtained by incubating mycelia of $P$. cactorum in sterilized tap water at $25^{\circ} \mathrm{C}$ for 2 days after mycelia were washed three times in sterilized tap water. 
purified isolates was amplified with the primers ITS1 (5'-TCCGTAGGT GAACCTGCGG-3') and ITS4 (5'-TCCTCCGCTTATTGATATGC-3') and sequenced. All eight isolates were identified as $P$. cactorum based on the ITS sequence and morphology of the pathogen (Harris 1979; Sewell and Wilson 1964; Upstone 1978). The isolates were inoculated in vitro on young Fuji apple fruit using a mycelial plug, and their pathogenicity was evaluated according to the diameter of the lesions developed on the fruit after 3 days. The most pathogenic isolate, APR310301, was stored at $5^{\circ} \mathrm{C}$, and was used in all experiments. The ITS sequence of the isolate was deposited in GenBank (accession ID MF362956).

Zoosporangia and zoospores were produced for all experiments described below by first growing isolate APR310301 on V8 agar for 3 to 4 days in darkness. Mycelial plugs ( $6 \mathrm{~mm}$ in diameter) from the edge of the colonies were inoculated in $100 \mathrm{ml}$ of liquid V8 medium $\left(10 \% \mathrm{~V} 8+2 \% \mathrm{CaCO}_{3}\right)$ in 250-ml Erlenmeyer flasks, with 12 plugs per flask. The flasks were incubated at $25^{\circ} \mathrm{C}$ for 3 days in darkness. After thorough washing three times with sterilized tap water, the mycelia were transferred to Petri dishes $(9 \mathrm{~cm}$ in diameter) containing $20 \mathrm{ml}$ of sterilized tap water, and incubated at $25^{\circ} \mathrm{C}$ for 2 days in darkness. When zoosporangia formed, the Petri dishes were placed in a refrigerator at $4^{\circ} \mathrm{C}$ for 1 to $2 \mathrm{~h}$ to release zoospores. Zoospore suspensions with a concentration of $1 \times 10^{4}$ zoospores $/ \mathrm{ml}$ were prepared for experiments described below. Zoospore suspensions were used within $20 \mathrm{~min}$.

Fruit used in all of the inoculation studies described below consisted of young Fuji apple fruit with a diameter of 4 to $7 \mathrm{~cm}$. The fruit were picked from an orchard at Jiaozhou Experiment Station of Qingdao Agricultural University, a site where no fungicides were applied during the experimental period from June to August 2015. Healthy fruit similar in size were chosen for inoculation the next day.

Effects of temperature on zoospore release. The effects of temperature on zoospore release in free water were tested at five temperatures $\left(0,5,10,15\right.$, and $\left.20^{\circ} \mathrm{C}\right)$. Release dynamics of zoospores

Table 1. Parameter estimates and statistics of the model describing the effects of temperature on Phytophthora cactorum zoospore release and germination

\begin{tabular}{lcc}
\hline Parameter $^{\mathbf{z}}$ & Zoospores release & Germination of zoospores \\
\hline$E$ & $28.58 \pm 1.32$ & $74.92 \pm 4.87$ \\
$F$ & $4.40 \pm 1.53$ & $28.60 \pm 1.31$ \\
$G$ & $0.28 \pm 0.06$ & $0.41 \pm 0.09$ \\
$H$ & $0.21 \pm 0.06$ & $4.07 \pm 1.16$ \\
$t_{\text {opt }}$ & 9.90 & 25.10 \\
$r_{y y}$ & 0.96 & 0.97 \\
LOF & 4.20 & 3.20 \\
$R^{2}$ & 0.14 & 0.73 \\
\hline
\end{tabular}

${ }^{\mathrm{z}} E, F, G$, and $H$ are parameters of model $f(w, t)=f(t)(1-\exp \{-[B(w-C)]\})$, where $f(t)=E^{\prime}\{\exp [(t-F) G /(H+1)]\} /\{1+\exp [(t-F) G]\}$ and $E^{\prime}=E[(H+$ $1) / H] H^{1 /(H+1)}$. Optimum temperature $\left(t_{o p t}\right)$ was calculated by $t_{\text {opt }}=F-(1 / G)$ $\ln (H), r_{\hat{y} y}$ is the correlation coefficient between observed values $(\bar{y})$ and predicted values $(\hat{y}), \mathrm{LOF}$ is the lack-of-fit value, and $R^{2}$ is the ratio of variation explained by the model to the variation of observed values. were examined at 11 sampling times (i.e., 15, 30, 60, and 90 min and $2,3,4,6,12,24$, and $48 \mathrm{~h}$ ). All zoosporangium suspensions, obtained as described above, were mixed together after filtering of mycelia through three to five layers of gauze. The suspensions were subsequently divided equally into 15 Petri dishes (each $9 \mathrm{~cm}$ in diameter). All 15 Petri dishes ( 3 per group) were immediately placed into five incubators set to the appropriate temperature in advance. At each time point, $300 \mu \mathrm{l}$ of zoospore suspension was sampled using a micropipette from three different sites in each Petri dish, $100 \mu \mathrm{l}$ from each site, and placed into a $1.5-\mathrm{ml}$ centrifuge tube. A drop of $0.1 \%$ cotton blue in lactophenol (lactic acid/phenol/glycerin/distilled water $[1: 1: 2: 1][\mathrm{vol} / \mathrm{vol} / \mathrm{vol} / \mathrm{vol}])$ was immediately added to each tube to kill the zoospores.

The zoospores in the suspension were counted with a hemocytometer under a microscope ( $\times 100$ magnification; Leica DM500). The zoospore concentration in each centrifuge tube was calculated three times, resulting in nine zoospore concentrations from each temperature and time combination. The experiment was replicated four times on different dates.

Effects of temperature and moisture level (free water and relative humidity) on zoospore germination. The effects of temperature on $P$. cactorum zoospore germination were assessed at seven temperatures $\left(5,10,15,20,25,30\right.$, and $\left.35^{\circ} \mathrm{C}\right)$. For each temperature, five moisture levels (free water and relative humidity [RH] of 100 , 99, 97, and 95\%) were set. Thus, there were 35 temperature-moisture combinations. The temperatures were controlled by seven incubators (MGC-250BP-2; Shanghai Bluepard Instruments Co. Ltd.), and the incubators were set to the required temperature $12 \mathrm{~h}$ prior to the experiment. RH values of $100,99,97$, and $95 \%$ were achieved by amending 2\% aqueous agar (Qing-dao Agar Powder Factory) with 0, 1.8, 5.2 , and $8.8 \mathrm{~g}$ of $\mathrm{NaCl}$ per $100 \mathrm{ml}$, respectively, in sealed dishes. The use of $\mathrm{NaCl}$ to achieve different moisture levels has been reported previously (Dong et al. 2006; Harris et al. 1970; Lang 1967; Li et al. 2003; Wang et al. 2015).

Two Petri dishes, each containing approximately $30 \mathrm{ml}$ of aqueous agar amended with the appropriate amount of $\mathrm{NaCl}$, were prepared for each temperature and moisture combination. One glass slide was placed in the lid of each of the 35 Petri dishes. Using a micropipette, two 20- $\mu$ l drops of zoospore suspensions were separately placed onto each of the two ends of the glass slide. After the two droplets had air dried at room temperature (ranging from 22 to $27^{\circ} \mathrm{C}$ ), the Petri dish was immediately sealed with Parafilm (National Can). Glass slides for the free water treatments were placed in Petri dishes containing $30 \mathrm{ml}$ of aqueous agar without $\mathrm{NaCl}$, and the droplets of zoospore suspension were not allowed to air dry before the dishes were sealed with Parafilm. All Petri dishes were immediately placed in incubators set to the appropriate temperature.

After $24 \mathrm{~h}$ of incubation, all dishes were taken out of the incubators, and a drop of $0.1 \%$ cotton blue in lactophenol was added to each spore suspension droplet to stop germination and kill the zoospores. The germination percentage of zoospores was estimated by randomly examining 20 zoospores in each of five microscope fields in each droplet $(\times 100$; Leica DM500). When the germ tube was longer than

Table 2. Means of Phytophthora cactorum zoospore germination percentages and corresponding standard deviations after incubation at different temperature (Temp) and humidity combinations for $24 \mathrm{~h}(2,000 \text { zoospores })^{\mathrm{z}}$

\begin{tabular}{|c|c|c|c|c|c|c|}
\hline \multirow[b]{2}{*}{$\operatorname{Temp}\left({ }^{\circ} \mathrm{C}\right)$} & \multicolumn{6}{|c|}{ Zoospore germination $(\%) \pm$ standard deviation } \\
\hline & Free water & $\mathbf{R H}=100 \%$ & $\mathbf{R H}=99 \%$ & $\mathbf{R H}=\mathbf{9 7 \%}$ & $\mathbf{R H}=\mathbf{9 5 \%}$ & Mean \\
\hline 5 & $15.6 \pm 5.6$ & $0.9 \pm 0.7$ & $2.6 \pm 3.9$ & $2.0 \pm 2.7$ & $3.7 \pm 5.1$ & $5.0 \pm 6.6 \mathrm{~b}$ \\
\hline 10 & $19.8 \pm 3.6$ & $2.7 \pm 3.1$ & $2.6 \pm 1.8$ & $0.9 \pm 1.1$ & $1.1 \pm 1.2$ & $5.4 \pm 7.7 \mathrm{~b}$ \\
\hline 15 & $52.8 \pm 11.7$ & $3.7 \pm 3.4$ & $4.7 \pm 5.1$ & $2.7 \pm 2.9$ & $2.1 \pm 2.3$ & $13.2 \pm 21.0 \mathrm{a}$ \\
\hline 20 & $60.3 \pm 16.6$ & $3.7 \pm 5.0$ & $4.6 \pm 5.3$ & $2.2 \pm 1.6$ & $2.0 \pm 1.3$ & $14.6 \pm 24.5 \mathrm{a}$ \\
\hline 25 & $70.5 \pm 10.1$ & $3.5 \pm 2.5$ & $2.6 \pm 2.0$ & $4.4 \pm 6.3$ & $3.4 \pm 3.2$ & $16.9 \pm 27.8 a$ \\
\hline 30 & $53.4 \pm 23.3$ & $3.6 \pm 6.1$ & $1.6 \pm 2.5$ & $1.7 \pm 2.3$ & $2.4 \pm 2.4$ & $12.5 \pm 23.1 \mathrm{a}$ \\
\hline 35 & $9.2 \pm 3.6$ & $2.6 \pm 2.5$ & $3.0 \pm 3.1$ & $1.2 \pm 1.3$ & $0.2 \pm 0.4$ & $3.4 \pm 4.1 \mathrm{~b}$ \\
\hline Mean & $41.0 \pm 25.7 \mathrm{a}$ & $3.0 \pm 3.6 \mathrm{~b}$ & $3.0 \pm 3.5 \mathrm{~b}$ & $2.2 \pm 3.0 \mathrm{~b}$ & $2.1 \pm 2.7 \mathrm{~b}$ & $10.1 \pm 19.2$ \\
\hline
\end{tabular}

${ }^{\mathrm{z}} \mathrm{RH}=$ relative humidity. Different letters indicate that the percentages are significantly different at the level of $\alpha=0.05$ according to multiple comparisons of values predicted by a generalized linear model. 
half of the total length of the zoospore, the zoospore was considered germinated. The experiment was replicated five times on different dates, and incubators were randomly assigned to the test temperatures in each replication.

Effects of temperature and wetness duration on zoospore infection. Effects of temperature and wetness duration on zoospore infection were examined at seven temperatures $(5,10,15,20,25,30$, and $35^{\circ} \mathrm{C}$ ) and 10 to 13 wetness duration treatments for each temperature. The wetness durations were $0,1,2,4,6,8,10,12,14,16,24$, and $48 \mathrm{~h}$ for temperatures of 15,20 , and $25^{\circ} \mathrm{C}$, beginning from 1 to $48 \mathrm{~h}$ for 10 and $30^{\circ} \mathrm{C}$ and from 2 to $48 \mathrm{~h}$ for 5 and $35^{\circ} \mathrm{C}$; at the unfavorable temperatures of $5,10,30$, and $35^{\circ} \mathrm{C}$, shorter wetness duration times could not be assessed because zoospore infections were slower and required longer incubation times. There were 81 temperature-wetness duration combinations in total, and five fruit were prepared for each combination.

The fresh fruit were placed into seven moistening vessels, which were used to control the wetness duration periods at the different temperatures for $12 \mathrm{~h}$ before inoculation. The moistening vessel consisted of a glass desiccator vessel, $40 \mathrm{~cm}$ in diameter, with a glass lid for sealing, which, furthermore, contained a horizontal separator with holes inside at the bottom. The separator provided a surface on which to place the fruit and a separate space at the bottom of the desiccator for adding $500 \mathrm{ml}$ of distilled water; this maintained the RH at $100 \%$. The fruit were inoculated by spraying the zoospore suspension using a hand sprayer until the suspension flowed down from the fruit surface. The inoculated fruit were then placed separately back onto the vessels, which were sealed immediately with the glass lid to maintain $\mathrm{RH}=100 \%$. The vessels were subsequently placed into the incubators at the relevant temperature. For the 0 -h treatment of wetness duration, five fruit were directly placed into the incubator set at the relevant temperatures after inoculation. For the other treatments, at the end of the specified wetness duration period, five fruit were randomly removed from the moistening vessel and placed at the relevant incubation temperature. Approximately 20 to $30 \mathrm{~min}$ were required for the suspension on the fruit surface to dry after the fruit were transferred to the incubator. Therefore, although the experimental setup was for wetness durations of $0,1,2,4,6,8,10,12,14,16$, 24 , and $48 \mathrm{~h}$, the actual wetness duration was approximately $0.5,1.5$, $2.5,4.5,6.5,8.5,10.5,12.5,14.5,16.5,24.5$, and $48.5 \mathrm{~h}$. Thus, the latter time points were used in all analyses. At $72 \mathrm{~h}$ after inoculation, all inoculated fruit were transferred to large chambers (MGC800B, a climate chamber; Shanghai Bluepard Instruments Co. Ltd.)

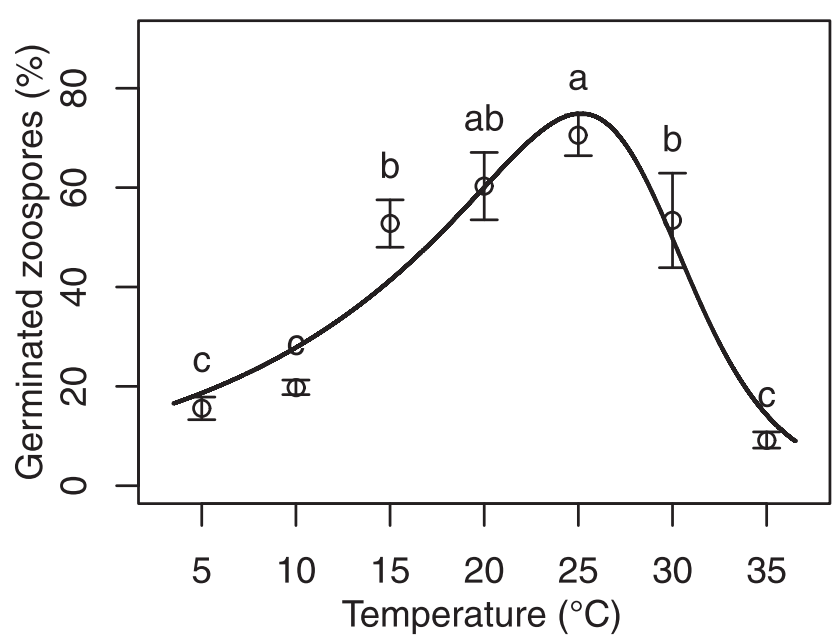

Fig. 3. Germination percentages of Phytophthora cactorum zoospores incubated in free water at seven temperatures for $24 \mathrm{~h}$. Circles are the means of observed values with standard errors (bar) and solid lines are the curves of the fitted models. Different letters indicate significant differences at the level of $\alpha=0.05$ according to multiple comparisons of values predicted by a generalized linear model with Tukey's all-pair comparisons test. Zoospores were obtained by placing the zoosporangium suspension at $5^{\circ} \mathrm{C}$ for $2 \mathrm{~h}$. maintained at $25^{\circ} \mathrm{C}$ and an $\mathrm{RH}$ of $75 \%$, which was achieved using a built-in humidifier. Lesions on each fruit were examined and recorded every 2 days from the 5 th to the 15 th day. Because the visible lesions began to merge and the lesion number began to decrease after 7 days, the number of lesions on each fruit at the seventh day was used in data analysis. The experiment was repeated four times on different dates from June to August 2015, and each incubator was randomly assigned to one of the tested temperatures in each replication.

Effects of temperature on lesion development. The effects of temperature on lesion development were examined at seven temperatures $\left(5,10,15,20,25,30\right.$, and $\left.35^{\circ} \mathrm{C}\right)$. Ten fruit were inoculated for each treatment by spraying the zoospore suspension, using a hand sprayer, until the suspension flowed down from the fruit surface. The inoculated fruit were immediately placed into four moistening vessels (as described above). The vessels were sealed with glass lids to maintain $\mathrm{RH}=100 \%$ and placed into a large chamber (MGC800B; Shanghai Bluepard Instruments Co. Ltd.) with the temperature set to $25^{\circ} \mathrm{C}$ in advance. After $24 \mathrm{~h}$, the fruit were removed, air dried, and placed into seven moistening vessels in which the $\mathrm{RH}$ was maintained at $75 \%$ by a saturated $\mathrm{NaCl}$ solution. The vessels were placed into seven incubators that had been set to the corresponding temperatures in advance. The percentage of lesion area compared with the entire surface of each fruit was estimated visually and recorded every day from the appearance of the first lesion until the 20th day. The incubation period was defined as the duration from inoculation to the first lesion symptom. The experiment was replicated four times on different dates from July to September 2015, and each incubator was randomly assigned to one of the tested temperatures in each replication.

Data analysis. Analysis of variance (ANOVA) was conducted using generalized linear models (GLM) to assess the effects of temperature and moisture on the germination and infection of zoospores as well as on lesion development. The replications of experiments on different days were treated as block factors, temperature was treated as a whole-plot factor, and moisture was treated as a subplot factor. The concentrations of zoospores in zoosporangium suspensions, the ratios of germinated zoospores, the number of lesions on each fruit on the seventh day, and the percentage of lesion areas compared with the entire surface of each fruit were applied in the data analysis and used to calculate means and standard deviations; the four variables were assumed to follow a Gaussian, Binomial, Poisson, and Binomial distribution, respectively, in GLM. Differences between treatments were determined by multiple comparisons of values using Tukey's all-pair comparisons, which was conducted via the method of glht in $\mathrm{R}$ (version 3.4.0). The Tukey test was calculated to identify significant differences between values at the $95 \%$ confidence interval.

Table 3. Parameter estimates and statistics of the model describing the effects of temperature and wetness duration on the infection of young apple fruit by zoospores of Phytophthora cactorum and disease development on fruit

\begin{tabular}{lcc}
\hline Parameter $^{\mathbf{z}}$ & Infection by zoospores & Disease development \\
\hline$B$ & $0.01 \pm 0.01$ & $0.17 \pm 0.02$ \\
$C$ & $0.40 \pm 0.97$ & $4.10 \pm 0.14$ \\
$E$ & $15.00 \pm 8.38$ & $94.97 \pm 3.09$ \\
$F$ & $24.74 \pm 0.56$ & $26.47 \pm 0.21$ \\
$G$ & $0.58 \pm 0.054$ & $0.58 \pm 0.03$ \\
$H$ & $2.63 \pm 0.61$ & $5.79 \pm 0.51$ \\
$t_{\text {opt }}$ & 23.00 & 23.50 \\
$r_{y y}$ & 0.97 & 0.95 \\
LOF & 0.44 & 1.20 \\
$R^{2}$ & 0.26 & 0.34 \\
\hline
\end{tabular}

${ }^{\mathrm{z}} B, C, E, F, G$, and $H$ are parameters of $f(t)=E^{\prime}\{\exp [(t-F) G /(H+1)]\} /\{1+$ $\exp [(t-F) G]\}$, in which $E^{\prime}$ is calculated by $E^{\prime}=E[(H+1) / H] H^{1 /(H+I)}$. Optimum temperature $\left(t_{\text {opt }}\right)$ was calculated by $t_{\text {opt }}=F-(1 / G) \ln (H), r_{\hat{y} y}$ is the correlation coefficient between observed values $(\bar{y})$ and predicted values $(\hat{y}), \mathrm{LOF}$ is the lack-of-fit value, and $R^{2}$ is the ratio of variation explained by the model to the variation of observed values. 
A temperature model (equations 1 and 2) was used to fit the concentration data for zoospores in zoosporangium suspensions and the data for zoospore germination to describe the effect of temperature on the release and germination of zoospores (Duthie 1997). Because zoospore release peaked at the fourth hour and yielded the highest zoospore quantities, the effect of temperature on zoospore release was modeled using the concentration data of zoospores at the release time point of the fourth hour:

$$
f(t)=E^{\prime}\{\exp [(t-F) G /(H+1)]\} /\{1+\exp [(t-F) G]\}
$$

where $E^{\prime}$ is calculated by

$$
E^{\prime}=E[(H+1) / H] H^{1 /(\mathrm{H}+1)}
$$

The modified version of the Weibull model (equations 1, 2, and 3 ) was applied to fit zoospore infection and disease development data to describe the effects of temperature, wetness duration, or incubation time on infection and disease development:

$$
f(w, t)=f(t)\left(1-\exp \left\{-[B(w-C)]^{\mathrm{D}}\right\}\right)
$$

where $t$ is temperature $\left({ }^{\circ} \mathrm{C}\right), w$ is the leaf wetness duration (hours) or incubation time (days), and $B, C, D, E, F, H$, and $G$ are the parameters to be estimated. The biological significance of the parameters has been described by Duthie (1997). The optimal temperature was calculated by:

$$
t_{\text {opt }}=F-(1 / G) \ln (H)
$$

The significance of the estimated parameters, correlation coefficient $r_{\hat{y} y}$ between observed $(\bar{y})$ and predicted $(\hat{y})$ (Arauz et al. 2010), $R^{2}$, and lack-of-fit (LOF) $F$ statistics (Zwietering et al. 1991) were calculated to evaluate the goodness of fit of the regression models. Nonlinear models were fitted to the data with the nlsLM method in R. The statistical analyses were performed using R (version 3.4.0).

\section{Results}

Effects of temperature on zoospore release. Temperature did not have a significant effect on the temporal release dynamics of zoospores. Zoospores were detected in all zoosporangium suspensions after incubation for $15 \mathrm{~min}$ at $0,5,10,15$, and $20^{\circ} \mathrm{C}$, and the average concentration of released zoospores at the five temperatures was $8.6 \times 10^{4} \mathrm{ml}^{-1}$. The concentration of zoospores gradually increased with elapsed time and reached its peak after $4 \mathrm{~h}$, when the highest concentration of zoospores was $22.4 \times 10^{4} \mathrm{ml}^{-1}$. The suspended

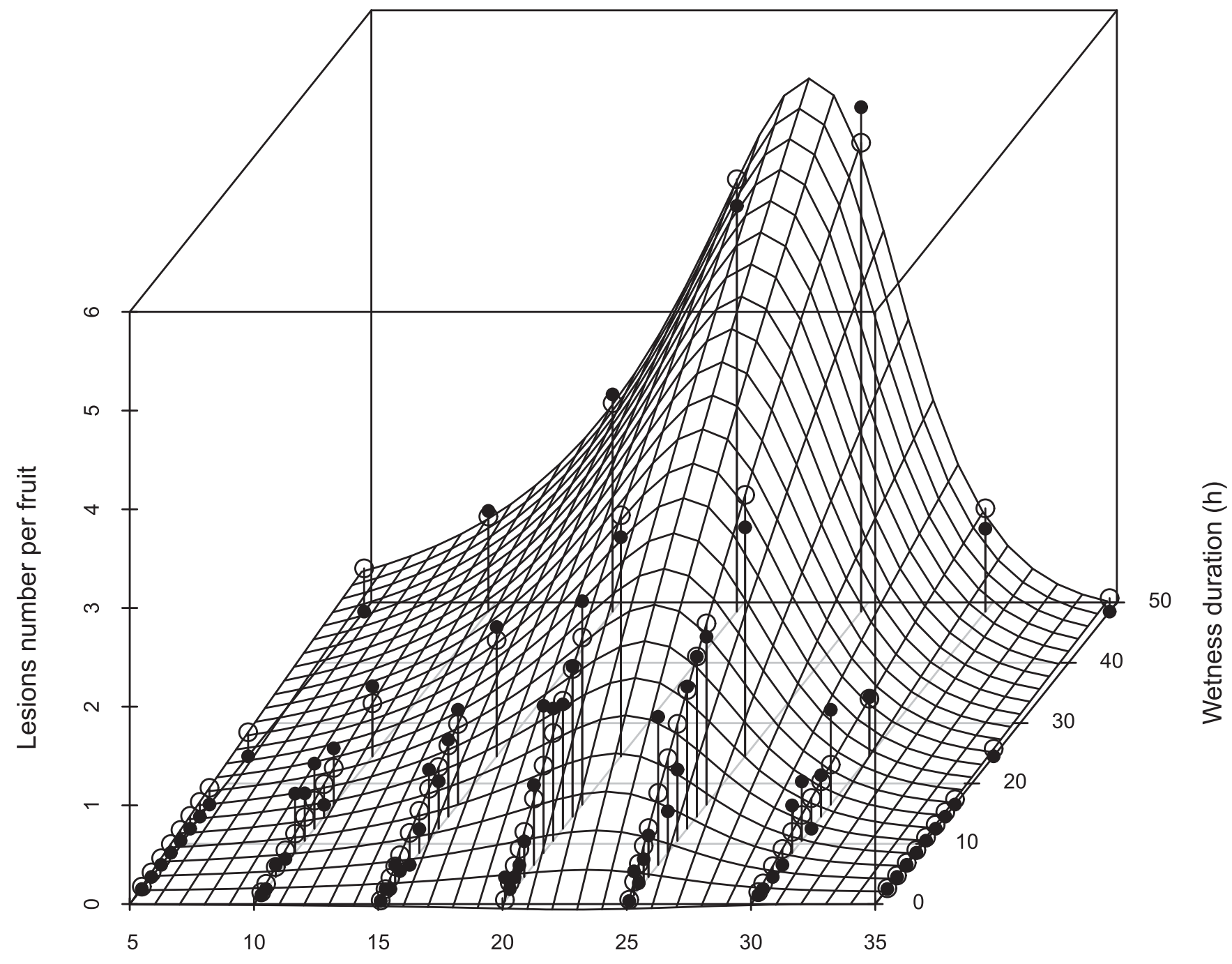

Temperature $\left({ }^{\circ} \mathrm{C}\right)$

Fig. 4. Number of lesions per apple fruit inoculated with Phytophthora cactorum zoospores and incubated at various combinations of temperature and wetness durations. Fruit were inoculated with a zoospore suspension of $P$. cactorum $\left(10^{4} \mathrm{zoospore} / \mathrm{ml}\right)$. After $72 \mathrm{~h}$, the inoculated fruit were moved to an incubator at $25^{\circ} \mathrm{C}$ and relative humidity of $75 \%$ and incubated for 4 days. The mesh is the curved surface of the fitted model. Dots are the means of the observed values and circles are the corresponding values predicted by the fitted model. 


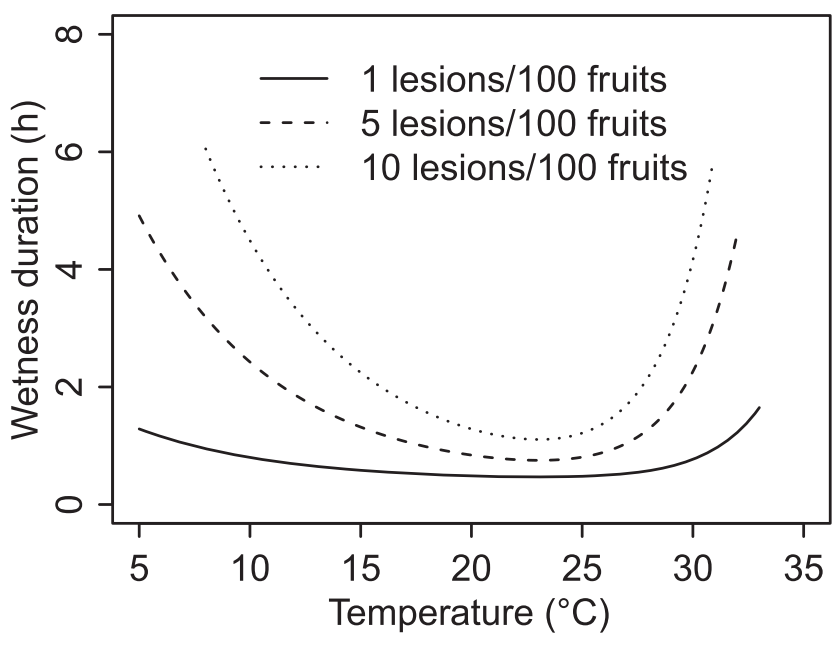

Fig. 5. Wetness duration required for zoospores of Phytophthora cactorum to complete infection and induce 1, 5, and 10 lesions on 100 apple fruit according to the fitted infection model. zoospores gradually became encysted with extended incubation times, and the concentration of motile zoospores thus decreased to $1.8 \times$ $10^{4} \mathrm{ml}^{-1}$ after $48 \mathrm{~h}$ (Fig. 2A).

Temperature had a significant $(P<0.001)$ influence on the quantity of zoospores. The concentrations of zoospores extracted after $4 \mathrm{~h}$ from suspensions incubated at $0,5,10,15$, and $20^{\circ} \mathrm{C}$ were $13.0 \times 10^{4}$, $22.9 \times 10^{4}, 30.4 \times 10^{4}, 23.5 \times 10^{4}$, and $22.1 \times 10^{4} \mathrm{ml}^{-1}$, respectively. The concentration of zoospores was significantly higher at $10^{\circ} \mathrm{C}$ than at the other four temperatures and significantly lower at $0^{\circ} \mathrm{C}$ than at the other four temperatures. However, no significant difference in zoospore concentration was found among 5,15 , and $20^{\circ} \mathrm{C}$ (Fig. 2B). The relationship between the concentration of zoospores after $4 \mathrm{~h}\left(f_{(t)} \times 10^{4} \mathrm{ml}^{-1}\right)$ and temperature $\left(t\right.$ in $\left.{ }^{\circ} \mathrm{C}\right)$ can be described by the temperature model (equations 1 and 2). The model accounted for $14.1 \%$ of the total variation among 384 observed values, and the correlation coefficient $r_{\hat{y} y}$ predicted by the model $(\hat{y})$ with the means $(\bar{y})$ of observed percentages at seven temperatures, was 0.96 (Table 1; Fig. 2B). An $F$ test did not indicate a significant LOF ( $\mathrm{LOF}=4.2, P=0.04$ ) between predictions from the fitted model and the observed zoospore concentrations (Table 1; Fig. 2B). The optimal temperature for zoospore release was $t_{o p t}=9.9^{\circ} \mathrm{C}$, based on the model.

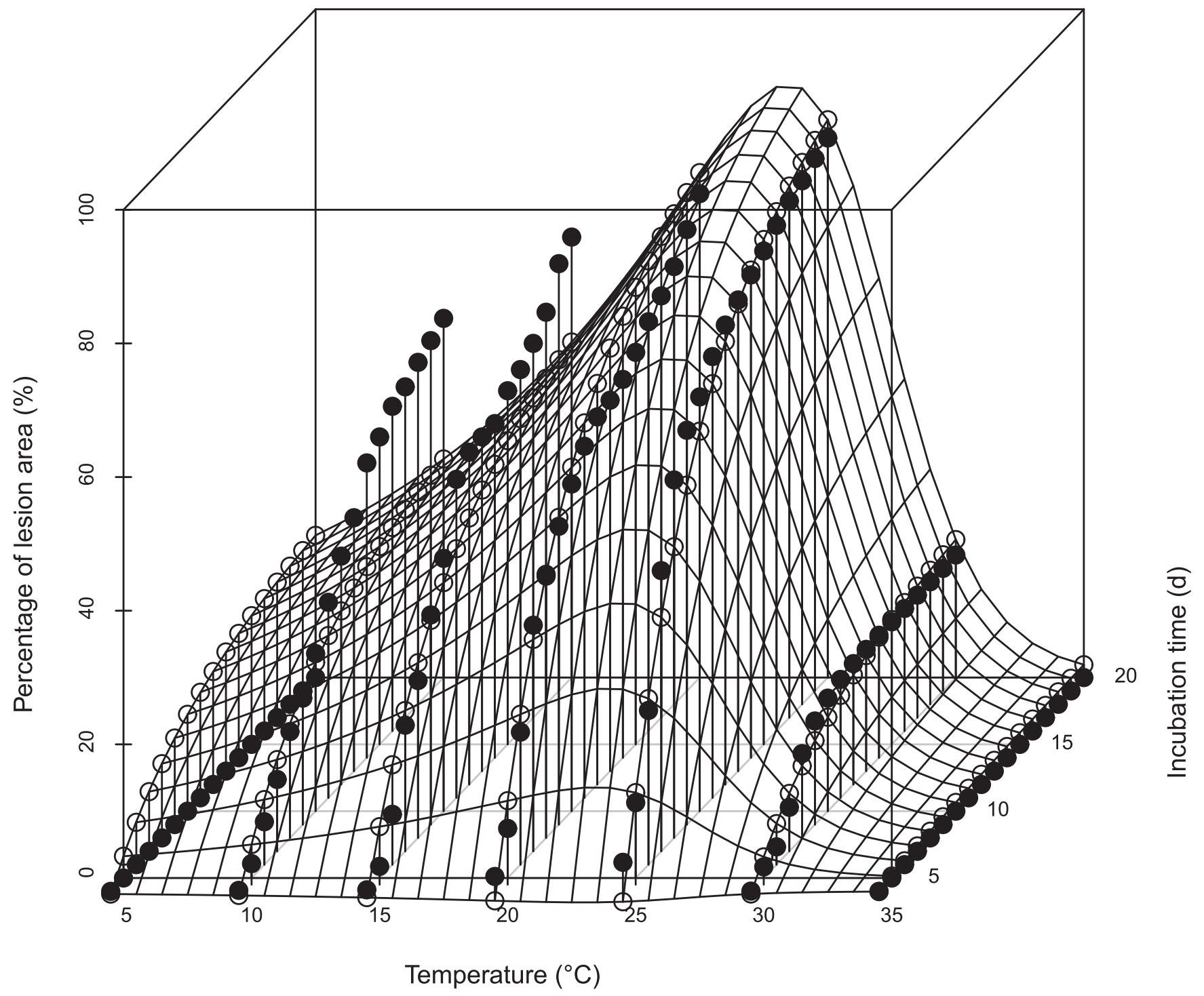

Fig. 6. Average percentage of lesion area on inoculated fruit incubated at various temperature-duration combinations. Fruit were inoculated by spraying a zoospore suspension of Phytophthora cactorum $\left(10^{4}\right.$ zoospore/ml), followed by incubation in an incubator at $25^{\circ} \mathrm{C}$ and relative humidity of $100 \%$ for $24 \mathrm{~h}$. Infected fruit were then moved to seven incubators and incubated at different temperatures. The mesh is the curved surface of the fitted model. Dots are the means of the observed values and circles are the corresponding values predicted by the fitted model. 
Effects of temperature and moisture level (free water and humidity) on zoospore germination. Temperature $(P<0.001)$ and moisture $(P<0.001)$ had a significant effect on in vitro zoospore germination of $P$. cactorum. The five moisture levels accounted for $62.8 \%$ of the total variation of zoospore germination percentages, though the seven temperature levels accounted for only $7.0 \%$ of the total variation. Germinated zoospores were observed at all seven tested temperatures in free water (Table 2). The average percentages of germinated zoospores across all humidity levels and in free water were $13.2,14.6,16.9$, and $12.5 \%$ at $15,20,25$, and $30^{\circ} \mathrm{C}$, respectively. These germination percentages were not significantly different from each other but were significantly higher than the germination rates at 5,10 , and $35^{\circ} \mathrm{C}$, which were $5.0,5.4$, and $3.4 \%$, respectively. The average germination percentage of zoospores across all temperatures in free water was $41.0 \%$ (Table 2), though it was no more than $3 \%$, on average, in environments without free water (RH of 95 to $100 \%$ ). This result indicated that germination of $P$. cactorum zoospores requires free water.

The relationship between the germination percentages of zoospores in free water and the seven tested temperatures was well fitted by the temperature model (equations 1 and 2). The model accounted for $73.1 \%$ of the total variation among 41 observed values, and the correlation coefficient $r_{\hat{y} y}$ was 0.97 (Fig. 3). An $F$ test did not indicate a significant $\mathrm{LOF}(\mathrm{LOF}=3.2, P=0.04$ ) between predictions from the fitted model and the observed zoospore concentrations (Table 1; Fig. 3 ). According to the model, the optimum temperature for zoospore germination was $25.1^{\circ} \mathrm{C}$.

Effects of temperature and wetness duration on zoospore infection. Temperature $(P<0.001)$ and wetness duration $(P<0.001)$ had a significant influence on infection by $P$. cactorum zoospores. Temperature accounted for $6.6 \%$ of the total variation of lesion number per fruit, and wetness duration accounted for $12.2 \%$ of the variation. PFR lesions were clearly observed on apple fruit inoculated at $10,15,20,25$, and $30^{\circ} \mathrm{C}$ after 4 days of incubation at $25^{\circ} \mathrm{C}$. Moreover, lesion numbers per fruit inoculated at 20 and $25^{\circ} \mathrm{C}$ were significantly higher than those inoculated at other temperatures. However, apple fruit inoculated at 5 and $35^{\circ} \mathrm{C}$ did not develop any visible lesions after 2 weeks of incubation at $25^{\circ} \mathrm{C}$ at all wetness duration treatments. The minimum wetness durations (MWD) for inoculation to result in visible lesions were $4.5,1.5,0.5,1.5$, and $8.5 \mathrm{~h}$ at 10,15 , 20,25 , and $30^{\circ} \mathrm{C}$, respectively. Lesion number increased with extended wetness duration when the MWD was satisfied. The relationship among change in lesion number per fruit $\left(f_{(t, w)}\right)$, temperature $\left(t,{ }^{\circ} \mathrm{C}\right)$, and wetness duration ( $w$, hours) was well fitted by the modified Weibull model (equations 1, 2, and 3). In the first set of analyses, the fitting of equation 3 to the infection data resulted in a singular gradient matrix at the initial parameter estimates. A six-parameter model without parameter $D$ was applied to fit the infection data in the second set of analyses. The second run generated the final estimates and their corresponding statistics (Table 3; Fig. 4). The model accounted for $26.0 \%$ of the total variation among 1,620 observed values, and the correlation coefficient $r_{\hat{y} y}$ was 0.97 . An $F$ test did not indicate a significant $\mathrm{LOF}(\mathrm{LOF}=0.44, P=0.9999$ ) between predictions from the fitted model and the observed lesion numbers. According to the fitted model, the optimal temperature for infection with $P$. cactorum zoospores was $t_{\text {opt }}=23.0^{\circ} \mathrm{C}$, and the largest lesion number resulting from inoculation was $E=15.0$. The MWD required for $P$. cactorum zoospores to successfully infect apple fruit was $0.40 \mathrm{~h}(C=0.40)$ at the optimal temperature (Table 3; Fig. 4). The wetness duration required for inoculation to induce 1,5 , and 10 lesions on 100 fruit was calculated from the fitted model (Fig. 5). The duration required for inoculation to induce 1 lesion on 100 fruit was $0.47 \mathrm{~h}$, approximately $28.2 \mathrm{~min}$, at the optimal temperature (Fig. 5).

Effects of temperature on fruit lesion development. Temperature had a significant $(P<0.001)$ effect on the development of PFR lesions. Visible lesions developed on fruit inoculated with zoospore suspensions after 4 days at $10,15,20,25$, and $30^{\circ} \mathrm{C}$. The lesion number on fruit incubated at $25^{\circ} \mathrm{C}$ was significantly higher than that at other temperatures. However, no lesions were found on fruit incubated for 20 days at 5 or $35^{\circ} \mathrm{C}$. The number of lesions increased and lesion areas enlarged with increasing incubation time, which resulted in the merging of visible lesions. The relationship between the development of disease lesions on each fruit, incubation temperature $\left(t,{ }^{\circ} \mathrm{C}\right)$, and incubation time ( $w$, days) was fitted by the modified Weibull model (equation 1). In the first analysis, the fitting of the model to the disease development data resulted in a singular gradient matrix at initial parameter estimates. Thus, the model was refitted as a six-parameter model without parameter $D$ to the disease development data to generate estimates and their corresponding statistics (Table 3; Fig. 6). The model accounted for $34.2 \%$ of the total variation among 7,140 observed disease development values, and the correlation coefficient $r_{\hat{y} y}$ was 0.95 . The $F$ test did not indicate a significant LOF ( $\mathrm{LOF}=1.2, P=0.03$ ) between the predictions from the fitted model and the observed lesion areas. According to the model, the optimal temperature for lesion development was $t_{\text {opt }}=23.5^{\circ} \mathrm{C}$, the minimum time for infected fruit to develop visible lesions was $C=4.1$ days, and the largest lesion area occupied $E=94.5 \%$ of the fruit surface after 20 days of incubation (Table 3; Fig. 6). In addition, the incubation times required for inoculation to result in lesion areas of $f_{(t, w)}=1$, 5 , and $10 \%$ of the fruit surface were calculated from the fitted model (Fig. 7). The incubation time required to induce $f_{(t, w)}=1 \%$ lesion area on inoculated fruit was $w=4.2$ days at the optimal temperature (Fig. 7).

\section{Discussion}

The temperature range required for infection of apple fruit by $P$. cactorum zoospores and disease development ranged from 10 to $30^{\circ} \mathrm{C}$, with an optimum of approximately $23^{\circ} \mathrm{C}$, even though zoospores can germinate at 5 and $35^{\circ} \mathrm{C}$. These findings were similar to those reported previously for the development of PFR (Grove and Boal 1991; Grove et al. 1985). Conducive temperatures of 5 to $35^{\circ} \mathrm{C}$ are common between apple tree bloom and fruit harvest of Fuji, the leading apple cultivar in China. Because temperatures in China may seldom limit the disease in apple production, long periods of rain, which affect not only infection but also the formation of sporangia, appear to be a crucial factor affecting PFR epidemics. The optimal temperature required for the release of zoospores from zoosporangium $\left(9.9^{\circ} \mathrm{C}\right)$ was much lower than that for zoospore germination and infection $\left(25.1^{\circ} \mathrm{C}\right)$. Low rainwater temperatures, in comparison with soil and fruit surface temperatures, will be conducive to and promote zoospore release because PFR epidemics are mainly driven by rainwater in China.

The germination and infection of $P$. cactorum zoospores require free water, similar to many other pathogens causing leaf and fruit diseases (Dong et al. 2006; Li et al. 2003; Sun et al. 2017; Wang et al. 2015). However, the wetness duration required for zoospore

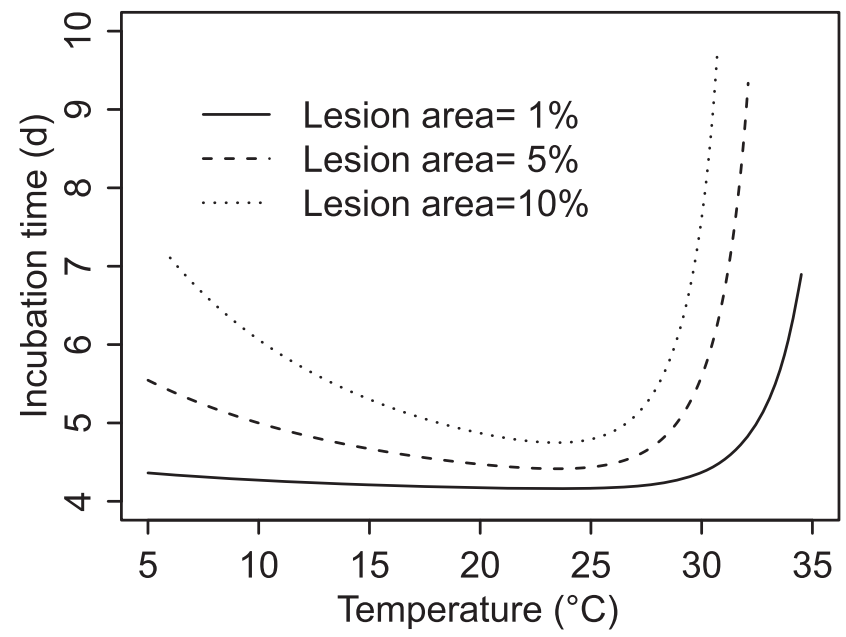

Fig. 7. Incubation times required for fruit inoculated with a zoospore suspension of Phytophthora cactorum $\left(10^{4}\right.$ zoospore/ml) to develop lesions covering 1,5 , and $10 \%$ of the fruit surface area according to the fitted disease development model. 
infection and the generation of visible lesions was very short; the observed value was half an hour at $20^{\circ} \mathrm{C}$. The MWD required for $P$. cactorum zoospore infection was $0.40 \mathrm{~h}(C=0.40$, about $24 \mathrm{~min})$ at the optimal temperature of $23.0^{\circ} \mathrm{C}$. The MWD is similar to that of cucumber downy mildew (Sun et al. 2017), and shorter than the MWD required for other leaf and fruit diseases caused by oomycetes (Arauz et al. 2010; Harris and Xu 2003; Timmer et al. 2000; Tooley et al. 2009), ascomycetes ( $\mathrm{Li}$ et al. 2003; Wang et al. 2015; Xu et al. 1995, 2001), and basidiomycetes (Dong et al. 2006). The short wetness duration period required for $P$. cactorum infection along with the 15-min wetness period required for zoosporangia to germinate and produce zoospores will frequently occur during rain events in seasons with high rainfall in China. Therefore, as long as zoosporangia have formed, a rain event that keeps fruit moist for nearly $1 \mathrm{~h}$ will be sufficient for infection, given the wetness duration required for formation and infection of zoospores.

The incubation period of PFR (that is, the duration from infection to first lesion occurrence) was found to be very short, approximately 4 days at the optimal temperature of $23.5^{\circ} \mathrm{C}$, according to the disease development experiments. Thus, there are only 3 or 4 days for growers to apply curative fungicides to control symptom onset once fruit are infected. Moreover, only a few fungicides can control pathogen growth and development in fruit. The curative and protective effects of 13 different fungicides have been tested (Liu et al. 2016). When applied 3 days before inoculation, all 13 fungicides achieved $100 \%$ control. However, when applied $24 \mathrm{~h}$ after zoospore inoculation, no effective control was observed; the curative effect of the most effective fungicides such as fosetyl-aluminum and propamocarb hydrochloride was about $60 \%$ (Liu et al. 2016). The most effective control measure will be an integrated management strategy, including (i) a reduction in the amount of primary inoculum of the pathogen in soil by removing diseased fruit from orchard, (ii) preventing zoosporangium formation on the soil surface by the timely draining of rainwater from soils to keep the soil dry or by applying thick mulches, (iii) killing newly formed zoosporangia on fruit and soil surfaces using fungicides, or (iv) preventing zoospore infections of fruit by using preventative fungicide applications. In order to prevent and control the disease effectively, the best time to apply fungicides in order to kill sporangia or protect fruit is before zoospores infect and after sporangia formed.

The development of a disease forecasting system for PFR using the information obtained in this study can aid in warning growers in advance when environmental conditions are predicted to be conducive to infection. The most important parameters will likely be low temperatures at the start of rain events, the duration of rain events, and sunny periods or wind following rain events that can assist in the drying of fruit. If there are sporangia and weather forecasts that predict these conditions, effective preventative application of fungicides can be employed. The conditions required for $P$. cactorum zoosporangium formation in soil, and factors determining the quantity and time required for the production of zoosporangia in lesions, should be investigated in the future to further try and improve disease management.

\section{Literature Cited}

Arauz, L. F., Neufeld, K. N., Lloyd, A. L., and Ojiambo, P. S. 2010. Quantitative models for germination and infection of Pseudoperonospora cubensis in response to temperature and duration of leaf wetness. Phytopathology 100:959-967.

Baines, R. C. 1939. Phytophthora trunk canker or collar rot of apple trees. J. Agric. Res. 59:159-184.

Banihashemi, Z., and Mitchell, J. 1976. Factors affecting oospore germination in Phytophthora cactorum, the incitant of apple collar rot. Phytopathology 66: 443-448.

Bhat, R. G., and Browne, G. T. 2010. Specific detection of Phytophthora cactorum in diseased strawberry plants using nested polymerase chain reaction. Plant Pathol. 59:121-129.

Blackwell, E. 1943. The life history of Phytophthora cactorum (Leb. \& Cohn) Schroet. Trans. Br. Mycol. Soc. 26:71-89.

Cheng, B., and Zhang, Y. 1981. Preliminary report on the investigation of apple phytophthora rot. Liaoning Fruit 1981:27-29. (In Chinese)

Dakwa, J., and Sewell, G. 1981. Influence of rootstock type and time of inoculation on the resistance of five apple scion cultivars to collar rot caused by Phytophthora cactorum. J. Hortic. Sci. 56:357-362.

Darmono, T. W., and Parke, J. L. 1990. Chlamydospores of Phytophthora cactorum: Their production, structure, and infectivity. Can. J. Bot. 68:640-645.
Dong, X. L., Li, B. H., Zhang, Z. F., Li, B. D., and Xu, X. M. 2006. Effect of environmental conditions on germination and survival of teliospores and basidiospores of the pear rust fungus (Gymnosporangium asiaticum). Eur. J. Plant Pathol. 115:341-350.

Duthie, J. 1997. Models of the response of foliar parasites to the combined effects of temperature and duration of wetness. Phytopathology 87:1088-1095.

Gisi, U., and Zentmyer, G. A. 1980. Mechanism of zoospore release in Phytophthora and Pythium. Exp. Mycol. 4:362-377.

Grove, G. G., and Boal, R. J. 1991. Influence of temperature and wetness duration on infection of immature apple and pear fruit by Phytophthora cactorum. Phytopathology 81:1465-1471.

Grove, G. G., Madden, L. V., Ellis, M. A., and Schmitthenner, A. F. 1985 Influence of temperature and wetness duration on infection of immature strawberry fruit by Phytophthora cactorum. Phytopathology 75:165-169.

Gupta, V., and Singh, K. 1979. Factors affecting the development of collar rot (Phytophthora cactorum) of apple [Faktoren, die entwicklung von Phytophthora cactorum bei apfel beeinflussen]. Gartenbauwissenschaft 44:29-32.

Han, J. 1979. Investigation of apple phytophthora rot. China Fruit 1979:58-63. (In Chinese).

Hantula, J., Lilja, A., Nuorteva, H., Parikka, P., and Werres, S. 2000. Pathogenicity, morphology and genetic variation of Phytophthora cactorum from strawberry, apple, rhododendron, and silver birch. Mycol. Res. 104: 1062-1068.

Harris, D. C. 1979. The occurrence of Phytophthora syringae in fallen apple leaves. Ann. Appl. Biol. 91:309-312.

Harris, D. C., and Tobutt, K. R. 1986. Factors influencing the mortality of apple seedlings inoculated with zoospores of Phytophthora cactorum (L. \& C.) Schroet. J. Hortic. Sci. 61:457-464.

Harris, D. C., and Xu, X. M. 2003. Conditions for infection of apple by Phytophthora syringae. J. Phytopathol. 151:190-194.

Harris, R. F., Gardner, W. R., Adebayo, A. A., and Sommers, L. E. 1970. Agar dish isopiestic equilibration method for controlling the water potential of solid substrates. Appl. Environ. Microbiol. 19:536-537.

Horner, I. J., and Wilcox, W. F. 1996. Spatial distribution of Phytophthora cactorum in New York apple orchard soils. Phytopathology 86:1122-1132.

Iribarren, M. J., Gonzalez, B., and Filippini, S. 2012. Distribución de Phytophthora cactorum en el perfil de un suelo cultivado con frutilla (Fragaria $\times$ ananassa) [Phytophthora cactorum distribution in a soil profile cultivated with strawberry (Fragaria $\times$ ananassa)]. Summa Phytopathol. 38:17-23.

Jacobs, K. A. 1994. First report of Phytophthora cactorum causing root and collar rot of apple in northeastern Spain. Plant Dis. 78:529.

Jeffers, S., and Aldwinckle, H. 1987. Enhancing detection of Phytophthora cactorum in naturally infested soil. Phytopathology 77:1475-1482.

Jeffers, S., and Aldwinckle, H. 1988. Phytophthora crown rot of apple trees: Sources of Phytophthora cactorum and P. cambivora as primary inoculum. Phytopathology 78:328-335.

Jung, T., and Blaschke, M. 2004. Phytophthora root and collar rot of alders in Bavaria: Distribution, modes of spread and possible management strategies. Plant Pathol. 53:197-208.

Lang, A. 1967. Osmotic coefficients and water potentials of sodium chloride solutions from 0 to $40^{\circ} \mathrm{C}$. Aust. J. Chem. 20:2017-2023.

Li, B., Zhao, H. W., and Xu, X. M. 2003. Effects of temperature, relative humidity and duration of wetness period on germination and infection by conidia of the pear scab pathogen (Venturia nashicola). Plant Pathol. 52:546-552.

Liu, F., Baohua, L. I., Liu, J., Dong, X., Wang, C., and Liang, W. 2016. Effects of several fungicides on controlling apple Phytophthora rot caused by Phytophthora cactorum. J. Fruit Sci. 2016:1269-1276. (In Chinese)

Liu, Y., He, Y., and Yang, J. 1998. Occurrence regularity and control measures of apple fruit Phytophthora rots. Hebei Fruits 1998:46-47. (In Chinese)

Matheron, M., Young, J., and Matejka, J. 1988. Phytophthora root and crown rot in apple trees in Arizona. Plant Dis. 72:481-484.

McIntosh, D. 1972. Effects of soil water suction, soil temperature, carbon and nitrogen amendments, and host rootlets on survival in soil of zoospores of Phytophthora cactorum. Can. J. Bot. 50:269-272.

Mircetich, S. M., Schreader, W., Moller, W. J., and Micke, W. 1976. Root and crown rot of cherry trees. Calif. Agric. 30:10-11.

Nakova, M. 2010. Phytophthora root and crown rot on apples in Bulgaria. Pestic. Fitomed. 25:43-50.

Nowakowska, J. A., Malewski, T., Tereba, A., and Oszako, T. 2016. Rapid diagnosis of pathogenic Phytophthora species in soil by real-time PCR. For. Pathol. 47:e12303.

Pánek, M., Fér, T., Mráček, J., and Tomšovský, M. 2016. Evolutionary relationships within the Phytophthora cactorum species complex in Europe. Fungal Biol. 120:836-851.

Sewell, G. W. F., and Wilson, J. F. 1964. Death of maiden apple trees caused by Phytophthora syringae Kleb. and a comparison of the pathogen with P. cactorum (L. \& C.) Schroet. Ann. Appl. Biol. 53:275-280.

Sewell, G. W. F., and Wilson, J. F. 1973a. Phytophthora collar rot of apple: Seasonal effects on infection and disease development. Ann. Appl. Biol. 74: 149-158.

Sewell, G. W. F., and Wilson, J. F. 1973b. Phytophthora collar rot of apple: Influence of the rootstock on scion variety resistance. Ann. Appl. Biol. 74: 159-169. 
Sewell, G. W. F., Wilson, J. F., and Dakwa, J. T. 1974. Seasonal variations in the activity in soil of Phytophthora cactorum, P. syringae and P. citricola in relation to collar rot disease of apple. Ann. Appl. Biol. 76:179-186.

Sneh, B., and McIntosh, D. 1974. Studies on the behavior and survival of Phytophthora cactorum in soil. Can. J. Bot. 52:795-802.

Spring, D. P. E., Ellis, M. A., Spotts, R. A., Hoitink, H. A. J., and Schmitthenner, A. F. 1980. Suppression of the apple collar rot pathogen in composted hardwood bark. Phytopathology 70:1209-1212.

Sun, S., Lian, S., Feng, S., Dong, X. L., Wang, C. X., Li, B., and Liang, W. 2017. Effects of temperature and moisture on sporulation and infection by Pseudoperonospora cubensis. Plant Dis. 101:562-567.

Suzui, T., and Hoshino, Y. 1979. Collar rot of apple caused by Phytophthora cambivora (Petri) Buism. Jpn. J. Phytopathol. 45:344-352.

Thomidis, T. 2001. Testing variability in pathogenicity of Phytophthora cactorum, $P$. citrophthora and $P$. syringae to apple, pear, peach, cherry and plum rootstocks. Phytoparasitica 29:47-49.

Thomidis, T. 2003. Influence of temperature and bark injuries on the development of Phytophthora cactorum and P. Citrophthora on peach trees. Sci. Hortic. (Amsterdam) 98:347-355.

Timmer, L. W., Zitko, S. E., Gottwald, T. R., and Graham, J. H. 2000. Phytophthora brown rot of citrus: Temperature and moisture effects on infection, sporangium production, and dispersal. Plant Dis. 84:157-163.

Tooley, P. W., Browning, M., Kyde, K. L., and Berner, D. K. 2009. Effect of temperature and moisture period on infection of rhododendron 'Cunningham's White' by Phytophthora ramorum. Phytopathology 99:10451052.

Tsao, P. H. 1983. Factors affecting isolation and quantitation of Phytophthora from soil. Pages 219-236 in: Phytophthora: Its Biology, Taxonomy, Ecology, and Pathology. D. C. Erwin, S. Bartnicki-García, and P. H.-t. Tsao, eds. American Phytopathological Society, St. Paul, MN.
Upstone, M. E. 1978. Phytophthora syringae fruit rot of apples. Plant Pathol. 27: 24-30.

Utkhede, R. 1986. Biology and control of apple crown rot caused by Phytophthora cactorum: A review. Phytoprotection 67:1-13.

Wang, B., Li, B., Dong, X., Wang, C., and Zhang, Z. 2015. Effects of temperature wetness duration, and moisture on the conidial germination, infection, and disease incubation period of Glomerella cingulata. Plant Dis. 99:249-256.

Wang, J., Xu, M., Zheng, P., Han, Y., Zhang, S., and Xu, M. 1991. Occurrence and control of apple fruit Phytophthora rot. Deciduous Fruits 1991:22-23. (In Chinese)

Webster, T., Tobutt, K., and Evans, K. 2000. Breeding and evaluation of new rootstocks for apple, pear and sweet cherry. Compact Fruit Tree 33:100-104.

Welsh, M. F. 1942. Studies of crown rot of apple trees. Can. J. Res. 20c:457-490.

Wormald, H. 1919. A phytophthora of pears and apples. Ann. Appl. Biol. 6: 89-100.

Xu, X. M., Butt, D. J., and Van Santen, G. J. 1995. A dynamic model simulating infection of apple leaves by Venturia inaequalis. Plant Pathol. 44:865-876.

Xu, X. M., Guerin, L., and Robinson, J. D. 2001. Effects of temperature and relative humidity on conidial germination and viability, colonization and sporulation of Monilinia fructigena. Plant Pathol. 50:561-568.

Yang, Z., and Liu, D. 1988. Epidemics of apple fruit Phytophthora rots in Shandong province. Yantai Fruits 1988:33-34. (In Chinese)

Yu, H., Liu, Z., Li, G., and Yang, H. 2011. Investigation of apple fruit Phytophthora rot of Liao-ning Yeng-kou. China Fruits 2011:68-69, 82. (In Chinese)

Zhou, J., and Zhao, S. 2016. Epidemics and control of apple fruit Phytophthora rots caused by Phytophthora cactorum. North. Fruit 2016:43-44. (In Chinese)

Zwietering, M. H., De Koos, J. T., Hasenack, B. B. E., De Witt, J. C., and Riet, K. V. 1991. Modeling of bacterial growth as a function of temperature. Appl. Environ. Microbiol. 57:1094-1101. 